\title{
Intestinal absorptive capacity, intestinal permeability and jejunal histology in HIV and their relation to diarrhoea
}

\author{
J Keating, I Bjarnason, S Somasundaram, A Macpherson, N Francis, A B Price, \\ D Sharpstone, J Smithson, I S Menzies, B G Gazzard
}

\begin{abstract}
Intestinal function is poorly defined in patients with HIV infection. Absorptive capacity and intestinal permeability were assessed using 3-O-methyl-D-glucose, D-xylose, L-rhamnose, and lactulose in 88 HIV infected patients and the findings were correlated with the degree of immunosuppression (CD4 counts), diarrhoea, wasting, intestinal pathogen status, and histomorphometric analysis of jejunal biopsy samples. Malabsorption of 3-Omethyl-D-glucose and D-xylose was prevalent in all groups of patients with AIDS but not in asymptomatic, well patients with HIV. Malabsorption correlated significantly $(r=0.34-0.56, p<0.005)$ with the degree of immune suppression and with body mass index. Increased intestinal permeability was found in all subgroups of patients. The changes in absorption-permeability were of comparable severity to those found in patients with untreated coeliac disease. Jejunal histology, however, showed only mild changes in the villus height/crypt depth ratio as compared with subtotal villus atrophy in coeliac disease. Malabsorption and increased intestinal permeability are common in AIDS patients. Malabsorption, which has nutritional implications, relates more to immune suppression than jejunal morphological changes. (Gut 1995; 37: 623-629)
\end{abstract}

Keywords: HIV, AIDS, intestinal permeability, intestinal function, intestinal infection, intestinal absorption.

Histopathology,

Northwick Park

Hospital, London

A B Price

Department of

Chemical Pathology,

St Thomas's Hospital,

London

I S Menzies

Department of Clinical Biochemistry, King's College School of Medicine and

Dentistry, London

I Bjarnason

S Somasundaram

A Macpherson

Correspondence to: Dr I Bjarnason, Department King's College School of King's College School of Medicine and Dentistry, Bessemer Road, London SE5 9PJ.

Accepted for publication 23 March 1995 the natural history of HIV, disease malabsor tion becomes evident and how it interrelates with symptoms of weight loss and diarrhoea.

We studied intestinal function with respect to absorption and permeability markers in a large group of patients with HIV infection at various stages and correlated the findings with symptoms of diarrhoea, weight loss, degree of immune suppression, and jejunal morphology. Patients with untreated coeliac disease have been used for comparison to enable functionalmorphometric interpretation of results in HIV patients with malabsorption.

\section{Subjects and methods}

\section{SUBJECTS}

Fifty seven healthy volunteers (21 women) acted as controls for the intestinal absorptionpermeability test (mean (SD) age 33 (7) years). Controls comprised 47 healthy, mainly medical and health service staff recruited for a number of previous studies conducted at Northwick Park Hospital and King's College Hospital and 10 men recruited from Chelsea Westminster Hospital during this study. None were at high risk for the HIV infection but they were not tested serologically before this study or subsequently.

Eighty eight HIV positive male homosexual patients were studied (mean (SD) age 39 (9) years). HIV was confirmed by both enzyme linked immunosorbent assay and western blot analysis. This group comprised 25 consecutive, well patients with HIV (out of $52(48 \%$ ) invited to participate) who had not had an AIDS defining illness and 22 (out of $43(51 \%)$ ) well patients with AIDS seeing a single physician in the Genitourinary Medicine outpatient department of Chelsea and Westminster Hospital. Patients who declined to participate in these studies did not differ significantly $(p>0.4)$ from those studied in respect of age, duration of AIDS, CD4 counts, body mass index, or serum albumin. The remainder comprised 34 consecutive inpatients with AIDS admitted to Chelsea and Westminster Hospital for gastrointestinal investigation who met the inclusion criteria (HIV positive, male homosexuals) and seven inpatients who were wasted but did not have gastrointestinal symptoms. Patients were specifically excluded if they had received a treatment course of antibiotics (including antimicrobial drugs) other than for Pneumocystis carinii prophylaxis in the preceding four weeks or if they required opioids for control of diarrhoea.

According to the revised classification system of the Centres for Disease Control, ${ }^{7}$ and taking into account the European modification of this classification, ${ }^{8} 25$ patients were at stage 2 - asymptomatic and without an AIDS 
TABLE I Demographic details of patients infected by HIV (values median (range))

\begin{tabular}{|c|c|c|c|c|c|}
\hline & \multirow[b]{2}{*}{ HIV (well) } & \multicolumn{4}{|l|}{ AIDS } \\
\hline & & Well & Wasted & $\begin{array}{l}\text { Pathogen } \\
\text { - ve } \\
\text { diarrhoea }\end{array}$ & $\begin{array}{l}\text { Pathogen } \\
+ \text { ve } \\
\text { diarrhoea }\end{array}$ \\
\hline $\begin{array}{l}\text { No of patients } \\
\text { Age (y) } \\
\text { Duration of AIDS }(\mathrm{mth})^{\star} \\
\text { CD4 counts } \dagger \\
\text { Body mass index } \ddagger \\
\text { Serum albumin }\end{array}$ & $\begin{array}{r}25 \\
37(25-54) \\
- \\
295(4-555) \\
24(18-28) \\
39(19-43)\end{array}$ & $\begin{array}{l}22 \\
39(27-48) \\
11(3-94) \\
67(8-171) \\
21(18-27) \\
37(21-49)\end{array}$ & $\begin{array}{l}7 \\
36(32-60) \\
6(4-26) \\
40(14-67) \\
16(14-19) \\
26(14-47)\end{array}$ & $\begin{array}{l}7 \\
39(33-50) \\
15(7-20) \\
18(2-44) \\
19(18-21) \\
32(26-38)\end{array}$ & $\begin{array}{l}27 \\
35(22-50) \\
23(3-46) \\
29(5-204) \\
18(14-23) \\
33(19-44)\end{array}$ \\
\hline
\end{tabular}

*From the time of an AIDS defining illness. There was no significant difference $(p>0.34)$ in the duration of AIDS between the subgroups.

†Lower limit of normal is 600 . HIV well patients had significantly $(p<0.025)$ greater CD4

counts than patients with AIDS apart from wasted AIDS patients $(p=0 \cdot 18)$. There was no

significant difference between the subgroups of patients with AIDS ( $>0.09$ ).

$\ddagger$ Lower limit of normal is 20 . The HIV well patients had significantly $(p<0.02)$ higher BMI

than the patients with AIDS apart from the AIDS well patients $(p=0.08)$

§Lower normal limit is $35 \mathrm{~g} /$. HIV well patients differed significantly $(\mathrm{p}<0.05)$ from wasted and

pathogen positive patients with AIDS, but there was otherwise no significant difference between

the various subgroups. diagnosed on the basis of significant diarrhoea and weight loss with a jejunal biopsy specimen showing subtotal villus atrophy, and all responded to a gluten free diet.

These studies were approved by the local ethical committees of Camberwell and Westminster Health Authorities and all patients gave informed consent.

\section{INVESTIGATIONS}

The AIDS patients underwent a standard diagnostic gastrointestinal protocol which has been detailed previously. ${ }^{9} 10$ Briefly, each was investigated by six stool examinations with light microscopy and culture, gastroduodenoscopy with duodenal aspiration and low duodenal (part 3) biopsy specimens, and sigmoidoscopy with rectal biopsy specimens. Well, stage 2 HIV patients had the stool examinations but not the endoscopies.

Body mass index (BMI: normal greater than 20) was calculated as weight $(\mathrm{kg}) /$ height $^{2}$ (m). ${ }^{11} \mathrm{CD} 4$ counts were assessed by flow cytometry and expressed as number of cells $\times 10^{6} / 1$. intestinal pathogen status as follows:

(i) AIDS well - 22 patients were asymptomatic with no history of weight loss or diarrhoea.

(ii) AIDS wasted - seven patients who had greater than $10 \%$ weight loss in the preceding month without any diarrhoea. Five had recently suffered from opportunistic infections $(P$ carinii $(n=4)$ and cytomegalovirus $(n=1))$. Two had Kaposi's sarcoma.

(iii) Thirty four patients had had diarrhoea (more than three liquid motions a day, for over a month). After investigation, detailed below, these were further separated into a group of seven in whom no intestinal pathogens were found (pathogen negative group) and the remaining 27 who had cryptosporidia $(n=17)$, microsporidia $(n=6)$, or both $(n=4)$. Demographic details of the HIV infected patients are shown in Table I.

Most of the patients were on drug treatment. Those with CD4 counts below 200 received treatment with dapsone $(100 \mathrm{mg} / \mathrm{d})$, pentamidine aerosol (300 mg/every third week) or co-trimoxazole (960 mg twice a day, three times per week) for $P$ carinii prophylaxis.

Five of 25 stage $2 \mathrm{HIV}$, well patients and 29 of the patients with AIDS had been on regular antiretroviral therapy (zidovudine) for over a month, but all of the AIDS patients had been on the drug at some stage. A further 15 patients with AIDS were receiving oral acyclovir (400-3000 mg/d) for perianal or genital Herpes and 20 were on keto-, flu- or itraconazole $(50-200 \mathrm{mg} / \mathrm{d})$ for antifungal prophylaxis. Drugs were withheld for 12 hours before the absorption-permeability tests. None of the drugs listed above are known to affect intestinal integrity. In particular, studies in six male homosexuals (HIV well without an AIDS defining illness) have shown that short term zidovudine ( 10 day treatment) does not interfere with intestinal permeability.

Ten patients with newly diagnosed and untreated coeliac disease acted as a comparative group for these studies. All had been

\section{JEJUNAL BIOPSY SPECIMENS AND}

MORPHOMETRIC ANALYSES

Thirty six stage 4 patients with AIDS, and all the patients with coeliac disease, underwent jejunal biopsy (Crosby capsule) just distal to the ligament of Treitz. Fifteen were from the AIDS well group and 21 with pathogen positive $(n=17)$ or pathogen negative $(n=4)$ diarrhoea. Morphometric analyses of jejunal biopsy samples was carried out by interactive image analyses (Joyce-Loebl magiscan) as previously described. ${ }^{12}$ The histological slides and morphometric analyses was shared equally between two histopathologist neither of whom had any knowledge of the diagnostic categories of the patients. An internal quality control showed an interobserver difference of less than $8 \%$ for the villus height and crypt depth measurements. Mucosal height was measured as the distance between muscularis mucosa and tips of well oriented, vertically sectioned villi. Crypt depth was measured as the distance between the basement membrane and the open 'mouth' of each crypt. At least eight measurements were made from each biopsy and the data were averaged.

Sixty patients in whom a jejunal biopsy had been carried out as a part of gastroenterological investigation and in whom a final diagnosis of irritable bowel syndrome had been made acted as controls for the morphometric studies. Biopsy specimens were not available from the HIV well patient group.

INTESTINAL ABSORPTION-PERMEABILITY TEST Following an overnight fast, subjects drank a $100 \mathrm{ml}$ test solution $(240 \mathrm{mOsm} / \mathrm{l})$ containing: - 3-O-methyl-D-glucose $(0 \cdot 2 \mathrm{G})$

- D-xylose $(0.5 \mathrm{~g})$

- L-rhamnose $(1.0 \mathrm{~g})$ 
TABLE II Five hour urine excretion of test substances (values median \% of dose excreted in five hours (interquartile range))

\begin{tabular}{|c|c|c|c|c|c|}
\hline & 3-O-m-glucose & $D$-xylose & L-rhamnose & Lactulose & Lactulose/L-rhamnose \\
\hline $\begin{array}{l}\text { Control }(n=57) \\
\text { HIV-well }(n=25) \\
\text { AIDS: }\end{array}$ & $\begin{array}{l}42 \cdot 5(39 \cdot 4-50 \cdot 0) \\
47 \cdot 8(42 \cdot 8-57 \cdot 5)\end{array}$ & $\begin{array}{l}29 \cdot 7(26 \cdot 2-34 \cdot 7) \\
39 \cdot 0(29 \cdot 0-43 \cdot 8)\end{array}$ & $\begin{array}{r}9 \cdot 9(8 \cdot 6-12 \cdot 3) \\
12 \cdot 3(7 \cdot 4-13 \cdot 7)\end{array}$ & $\begin{array}{l}0.23(0.21-0.39) \\
0.38(0.25-0.60)\end{array}$ & $\begin{array}{l}0.03(0.02-0.03) \\
0.04(0.03-0.07)\end{array}$ \\
\hline $\begin{array}{l}\text { Well }(n=22) \\
\text { Wasting }(n=7) \\
\text { Path - ve }(n=7) \\
\text { Path +ve }(n=27) \\
\text { Coeliac disease }(n=10)\end{array}$ & $\begin{array}{l}41 \cdot 2(24 \cdot 7-54 \cdot 0) \\
27 \cdot 0(16 \cdot 0-42 \cdot 5) \dagger \\
37 \cdot 5(23 \cdot 6-40 \cdot 4) \dagger \\
27 \cdot 7(13 \cdot 0-33 \cdot 6) \dagger \\
29 \cdot 2(23 \cdot 3-38 \cdot 4) \dagger\end{array}$ & $\begin{array}{c}23 \cdot 3(16 \cdot 4-30 \cdot 9) \\
15 \cdot 0(8 \cdot 8-27 \cdot 6) \dagger \\
14 \cdot 2(6 \cdot 9-23 \cdot 8) \dagger \\
9 \cdot 6(6 \cdot 5-17 \cdot 2) \dagger \\
18 \cdot 7(13 \cdot 1-22 \cdot 4) \dagger\end{array}$ & $\begin{array}{l}5 \cdot 1(3 \cdot 8-9 \cdot 3) \dagger \\
2 \cdot 8(2 \cdot 2-8 \cdot 4) \dagger \\
4 \cdot 7(1 \cdot 1-7 \cdot 0) \dagger \\
2 \cdot 2(1 \cdot 3-5 \cdot 0) \dagger \\
4 \cdot 8(4 \cdot 1-6 \cdot 6) \dagger\end{array}$ & $\begin{array}{l}0.38(0.19-0.52)^{\star} \\
0.61(0.31-0.69)^{\star} \\
0.32(0.17-0.73)^{\star} \\
0.44(0.21-1 \cdot 10)^{\star} \\
0.55(0.22-1.01)^{\star}\end{array}$ & $\begin{array}{l}0.06(0.04-0.11) \dagger \\
0.12(0.07-0.16) \dagger \\
0.15(0.07-0.19) \dagger \\
0.26(0.08-0.33) \dagger \\
0.12(0.07-0.17) \dagger\end{array}$ \\
\hline
\end{tabular}

${ }^{\star}$ Differs significantly from control $p<0 \cdot 05$. $†$ Differs significantly from control $p<0.01$.

- Lactulose $(5 \cdot 0 \mathrm{~g})(7 \cdot 5 \mathrm{ml}$ Duphalac syrup; $67 \%$ lactulose w/v syrup)

The solution was designed to assess active and passive carrier mediated transport and intestinal permeability (lactulose/L-rhamnose), respectively. Food and fluid were allowed two hours later. Complete urine collections into a contained containing $1 \mathrm{ml}(19 \% \mathrm{w} / \mathrm{v})$ mercurithiosalicylate (Merthiolate) as preservative for the sugar markers were made for five hours. Analysis of the sugar probes was done by a thin layer technique, as previously described, ${ }^{13}$ which is both accurate and sensitive. All subjects abstained from alcohol for at least a week before the test, ${ }^{14}$ no patient was taking non-steroidal anti-inflammatory drugs ${ }^{15}$ or had medical conditions which are known to be associated with increased intestinal permeability. ${ }^{1617}$

\section{STATISTICAL ANALYSIS}

Statistical differences between groups was assessed by the Mann-Whitney $U$ test.
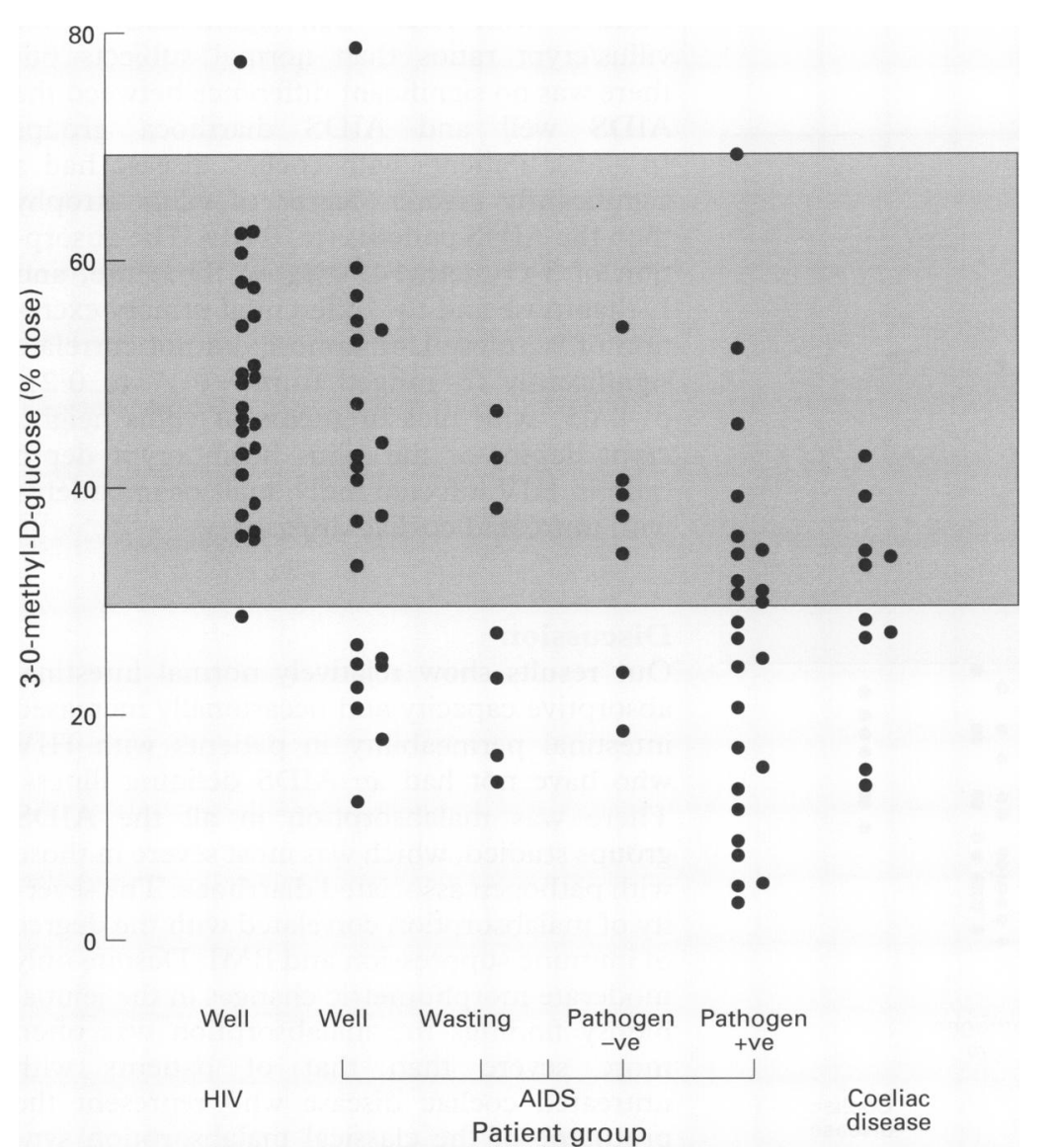

Figure 1: Five hour urinary excretion of 3-O-methyl-D-glucose from patients with $\mathrm{HIV}$ infection and coeliac disease. The shaded area represents the normal test range.
Spearman's correlation coefficient was employed for the assessment of correlation's between parameters.

\section{Results}

INTESTINAL ABSORPTION AND PERMEABILITY

Table II shows the mean five hour urine excretion of the test substances from HIV infected patients and patients with coeliac disease. There was no significant difference between the HIV well patients and normal subjects. Patients with AIDS who were well had significant $(p<0.01)$ malabsorption of L-rhamnose but not that of 3-O-methyl-D-glucose or Dxylose. Other patients with AIDS (wasted, pathogen negative and pathogen positive diarrhoea) had significant malabsorption of all three monosaccharides and to a similar or greater extent than patients with untreated coeliac disease.

Figures 1, 2, and 3 show the individual monosaccharide urine excretion data from the study groups. Malabsorption of monosaccharides was rare in patients with HIV stage 2 . Patients with AIDS had variable prevalence of malabsorption of monosaccharides (Figs 1-3) ranging from $30 \%$ (seven of 23) AIDS well patients with malabsorption of $\mathrm{D}$-xylose to $89 \%$ (24 of 27) AIDS patients with pathogen positive diarrhoea with malabsorption of $\mathrm{L}$ rhamnose. AIDS patients with diarrhoea had significantly $(p<0.01)$ greater malabsorption of the three monosaccharides than HIV well patients or AIDS patients without diarrhoea. Malabsorption in the AIDS patients was in many cases more severe than found in untreated coeliac disease.

The differential urinary lactulose/L-rhamnose excretion showed some striking changes (due to increased lactulose and decreased L-rhamnose urine excretion) and are shown in Figure 4. Five of $25(20 \%)$ stage 2 patients had increased intestinal permeability. All the AIDS groups had significantly increased intestinal permeability with a frequency ranging from $50 \%$ (11 of 22) in well patients to nearly $100 \%$ in the other groups. AIDS patients with diarrhoea had significantly $(p<0.01)$ greater changes in intestinal permeability than HIV well patients or AIDS patients without diarrhoea. The permeability changes in patients with AIDS were comparable to or more severe than those of the 10 untreated patients with coeliac disease.

There was a significant correlation between a rise in different urine excretion of lactulose/Lrhamnose and a depression in the absorption of 
3-O-methyl-D-glucose $(\mathrm{r}=-0.38, \mathrm{p}<0.001)$, and $\mathrm{D}$-xylose $(\mathrm{r}=-0.56, \mathrm{p}<0.001)$ in HIV infected patients. The permeability changes
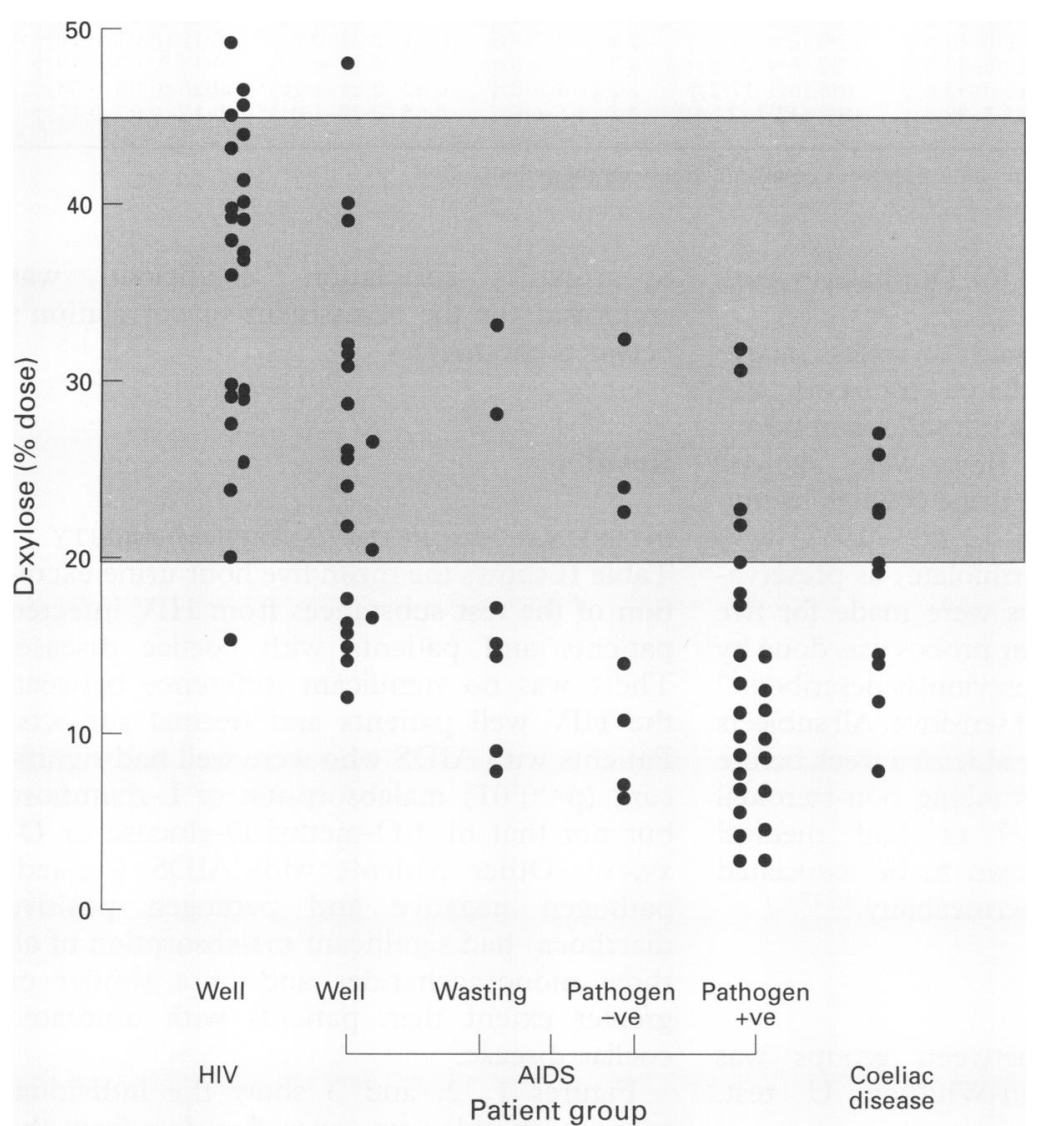

Figure 2: Five hour urinary excretion of D-xylose. The shaded area represents the normal test range.

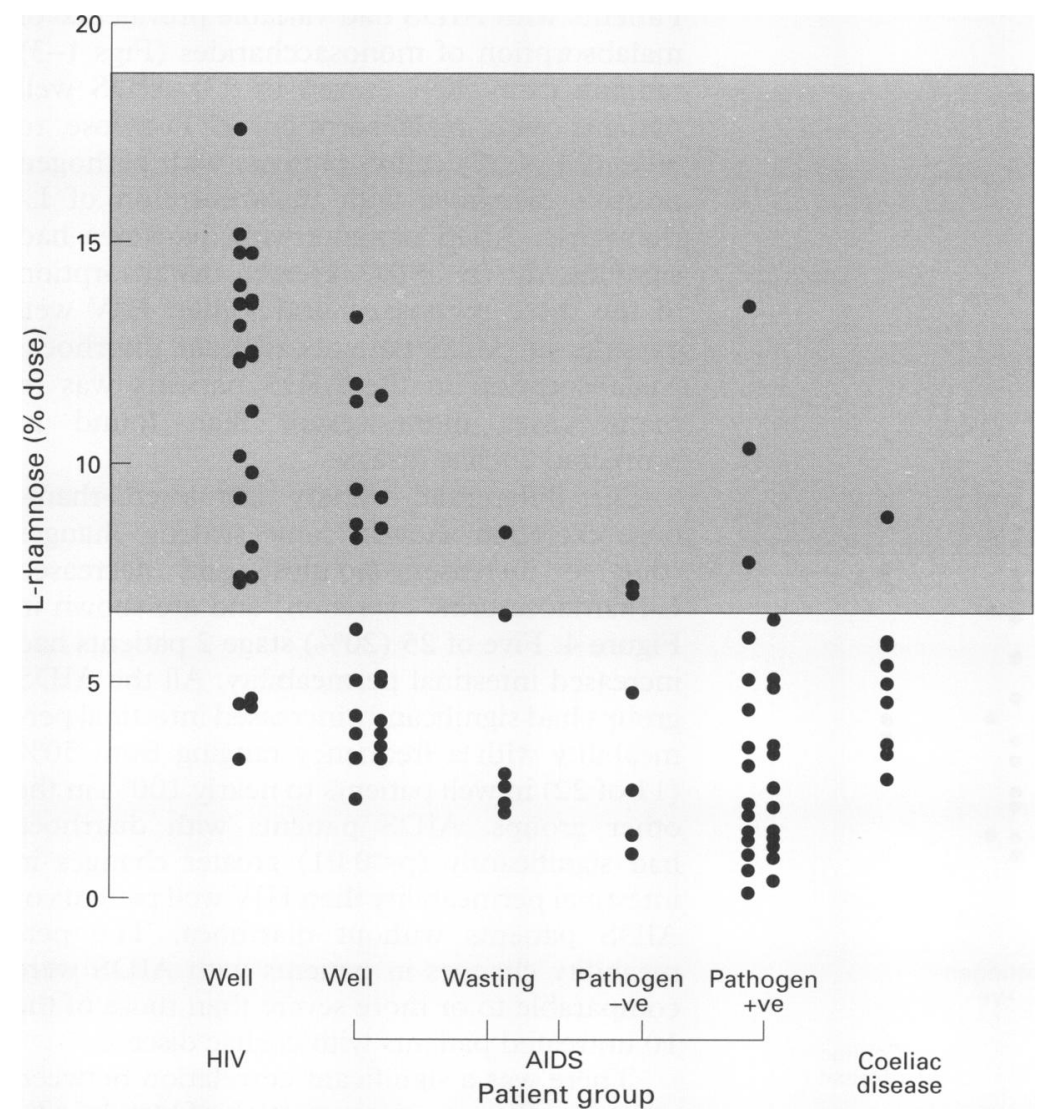

Figure 3: Five hour urinary excretion of L-rhamnose. The shaded area represents the normal test range.
(lactulose/L-rhamnose) correlated significantly with BMI $(r=20.36, p<0.003)$, and $\mathrm{CD} 4$ counts $(=-0.34, \mathrm{p}<0.006)$ but not with serum albumin $(\mathrm{r}=-0.13, \mathrm{p}>0.20)$.

There was a significant correlation between BMI and the absorption of 3-O-methylD-glucose $\quad(\mathrm{r}=0.34, \quad \mathrm{p}<0.001), \quad \mathrm{D}$-xylose $(\mathrm{r}=0.52, \mathrm{p}<0.001)$, and L-rhamnose $(=0.47$, $\mathrm{p}<0.001)$. There was also a significant correlation between $C D$ counts and the absorption of 3-O-methyl-D-glucose $(\mathrm{r}=0.43, \mathrm{p}<0.001)$. D-xylose $(r=0.54, p<0.001)$, and L-rhamnose $(r=0.43, p<0.001)$. Serum albumin concentrations correlated significantly with 3-Omethyl-D-glucose $(r=0 \cdot 22, p<0 \cdot 05), D$-xylose $(r=0.31, p<0.01)$, and L-rhamnose $(r=0.27$, $\mathrm{p}<0.03)$.

The possible effect of zidovudine was assessed by comparing intestinal absorptive capacity and intestinal permeability between the AIDS patients who were taking $(n=29)$ and not taking $(n=37)$ the drug. There was, however, no significant difference $(p>0 \cdot 17)$ in these parameters between these groups.

\section{HISTOMORPHOMETRIC ANALYSIS OF JEJUNAL} BIOPSY SAMPLES

Table III shows the villus height and crypt depth from controls, patients with AIDS, and patients with coeliac disease. The villus height in patients with AIDS was within the control range but the crypt depth was significantly increased $(p<0.001)$. Figure 5 shows the villus/crypt ratio, which is a proposed quantitative measure of the degree of villus atrophy. Patients with AIDS had significantly lower villus/crypt ratios than normal subjects but there was no significant difference between the AIDS well and AIDS diarrhoea groups $(p>0.5)$. Patients with coeliac disease had a significantly greater degree of villus atrophy than the AIDS patients $(p<0 \cdot 01)$. The absorption of 3-O-methyl-D-glucose, D-xylose, and L-rhamnose and the differential urinary excretion of lactulose/L-rhamnose did not correlate significantly ( $r=$ ranged from -0.17 to 0.21 , $p>0.05$ ) with measurements of villus height, crypt depth, or the villus height/crypt depth ratio in HIV infected individuals or in patients with untreated coeliac disease.

\section{Discussion}

Our results show relatively normal intestinal absorptive capacity and occasionally increased intestinal permeability in patients with HIV who have not had an AIDS defining illness. There was malabsorption in all the AIDS groups studied, which was most severe in those with pathogen associated diarrhoea. The severity of malabsorption correlated with the degree of immune suppression and BMI. Despite only moderate morphometric changes in the jejunal biopsy findings the malabsorption was often more severe than that of patients with untreated coeliac disease who represent the prototype of the classical malabsorption syndrome. Intestinal permeability was significantly increased in all the subgroups of AIDS 


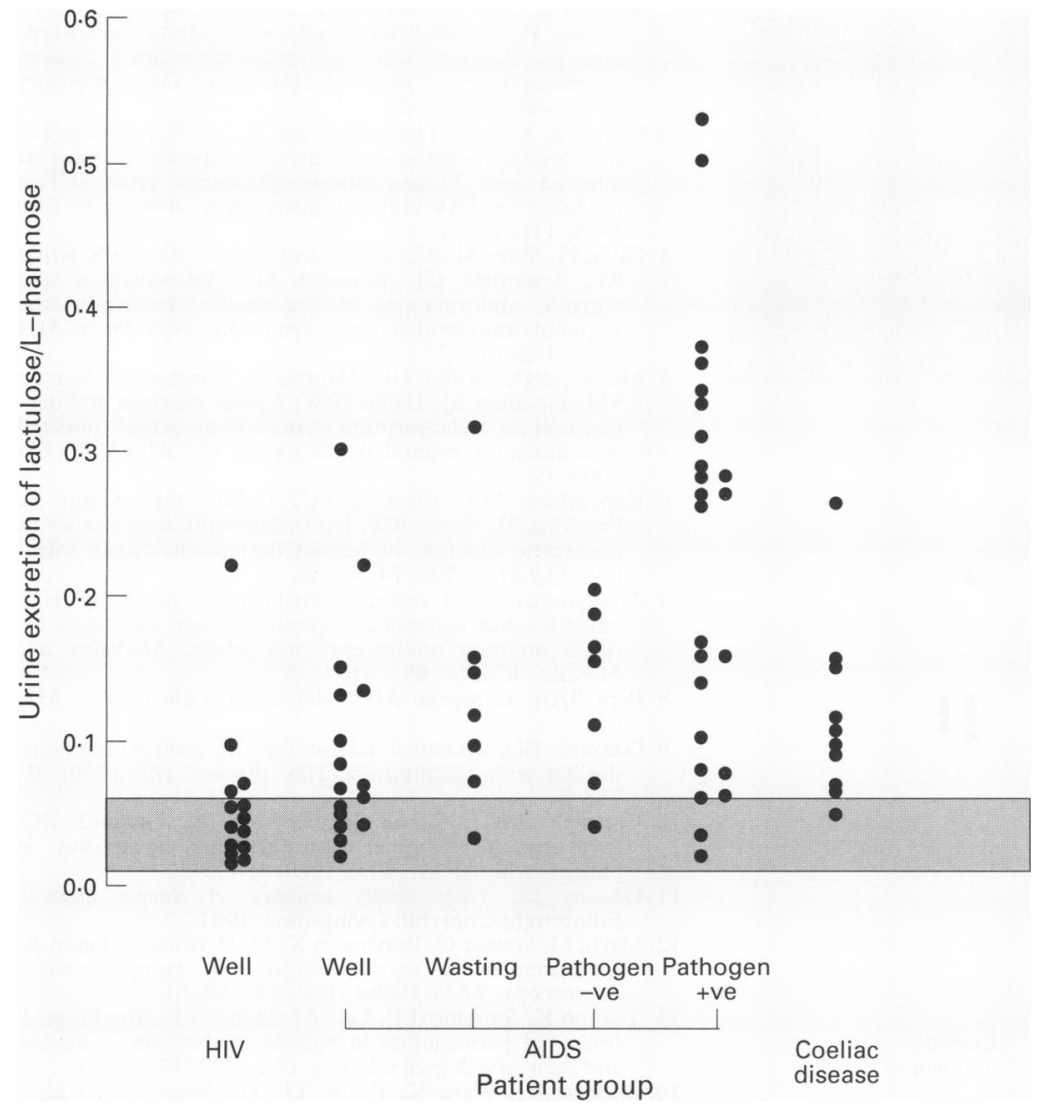

Figure 4: Differential urinary excretion of lactulose/L-rhamnose. The shaded area represents the normal test range.

and also correlated significantly with $\mathrm{CD} 4$ counts and BMI.

Malabsorption and increased intestinal permeability in patients with AIDS have different pathophysiological implications. The former may contribute to malnutrition and wasting while the latter may be important in predisposing to the development of a non-specific enteropathy. ${ }^{18-20}$

Previous studies assessing malabsorption in HIV infected patients have often employed a large test dose of D-xylose ( $25 \mathrm{~g})$, which may in itself interfere with intestinal absorption. ${ }^{21}$ Nevertheless, the impression is that patients with AIDS may have malabsorption, particularly those with cryptosporidial associated diarrhoea. ${ }^{1-4}$ The prevalence of malabsorption has ranged from $28 \%$ to $100 \%$, but the studies are confounded by the small numbers of patients studied and, at times, by inadequate description of the disease stage. We have not found significant malabsorption in asymptomatic HIV infected patients without AIDS. Many patients with AIDS, however, had evidence of malabsorption irrespective of symptoms, and in agreement with Kotler et al ${ }^{1}$ and Miller et $a l^{2}$ this was most severe in those

TABLE III Morphometric analyses of jejunal biopsy samples (values median (interquartile range))

\begin{tabular}{llll}
\hline Patient group (no) & Villus height $(\mu m)$ & Crypt depth $(\mu m)$ & Villus/crypt ratio \\
\hline Normal (60) & $510(461-566)$ & $133(126-148)$ & $3 \cdot 65(3 \cdot 23-4 \cdot 08)$ \\
AIDS well (15) & $564(483-629)$ & $229(192-294)^{\star}$ & $2 \cdot 40(2 \cdot 00-2 \cdot 60)^{\star}$ \\
AIDS diarrhoea (22) & $560(500-638)$ & $247(174-290)^{\star}$ & $2 \cdot 25(2 \cdot 00-2 \cdot 73)^{\star}$ \\
Coeliac disease (10) & $422(398-461)^{\star}$ & $364(334-392)^{\star}$ & $1 \cdot 19(1 \cdot 15-1 \cdot 26)^{\star}$ \\
\hline
\end{tabular}

$\star$ Differed significantly from normals $\mathrm{p}<0.001$. with diarrhoea due to cryptosporidial or microsporidial infection. The jejunal morphometric findings frequently showed predominant crypt cell hyperplasia, in agreement with previous studies, ${ }^{1-5} 22$ and only mild changes in the villus height/crypt depth ratio, which is a sensitive indicator of villus atrophy. ${ }^{12}$ However, a previous study using different methods of histomorphometric analyses of jejunal biopsy samples, showed a significant correlation between the degree of mild partial villus atrophy and malabsorption parameters in HIV disease ${ }^{5}$ suggesting a structure-function relationship. We and others ${ }^{4}$ have not found this to be the case nor was there a significant correlation between the absorption or permeability parameters and the histological findings in patients with coeliac disease, in keeping with previous results. ${ }^{23} 24$ If jejunal morphological changes (which may not be representative of the state of the more distal small intestine) were solely responsible for the malabsorption, it might be expected that patients with untreated coeliac disease would have more severe malabsorption than the AIDS patients. Indeed Ehrenpreis et $a l,{ }^{25}$ who assessed the kinetics of D-xylose absorption and disappearance following intravenous administration, concluded that the absorption constant of D-xylose was reduced out of proportion to the histological abnormalities of duodenal biopsy specimens in patients with AIDS.

The significant correlation in our study between the malabsorption parameters with the degree of immune suppression and BMI suggests that the reduced CD4 counts predispose to an intestinal infection or promote proliferation of the HIV within the intestine ${ }^{26} 27$ (such as is the case in hepatitis A and rotavirus infections ${ }^{28}{ }^{29}$ ) and the resulting malabsorption contributes to the wasting of these patients. This is clearly not the only explanation as some patients had wasting and normal absorptive capacity and vice versa, and many of those with severe diarrhoea had normal absorptive capacity while some without diarrhoea had malabsorption. This re-emphasises the multifactorial pathogenic mechanisms responsible for the clinical status of patients with AIDS.

Increased intestinal permeability was more common than malabsorption in patients with AIDS. Furthermore, the intestinal permeability changes were comparable or greater than those found in patients with untreated coeliac disease. There are only a few studies which have addressed intestinal permeability changes in HIV infection. Kapembwa et al reported increased intestinal permeability in AIDS patients with diarrhoea but findings in asymptomatic patients were normal. ${ }^{30}$ However, there were methodological problems with analysis of sugars ${ }^{31}$ and the question of 'topical enteropathy' in the Zambian subjects was not taken into account. ${ }^{32} 33$ In agreement with our findings, Ott et al found an increased permeability in patients with AIDS regardless of intestinal symptoms, which was most noticeable in patients with intestinal cryptosporidial infection and quantitatively comparable with that of patients with Crohn's and coeliac 


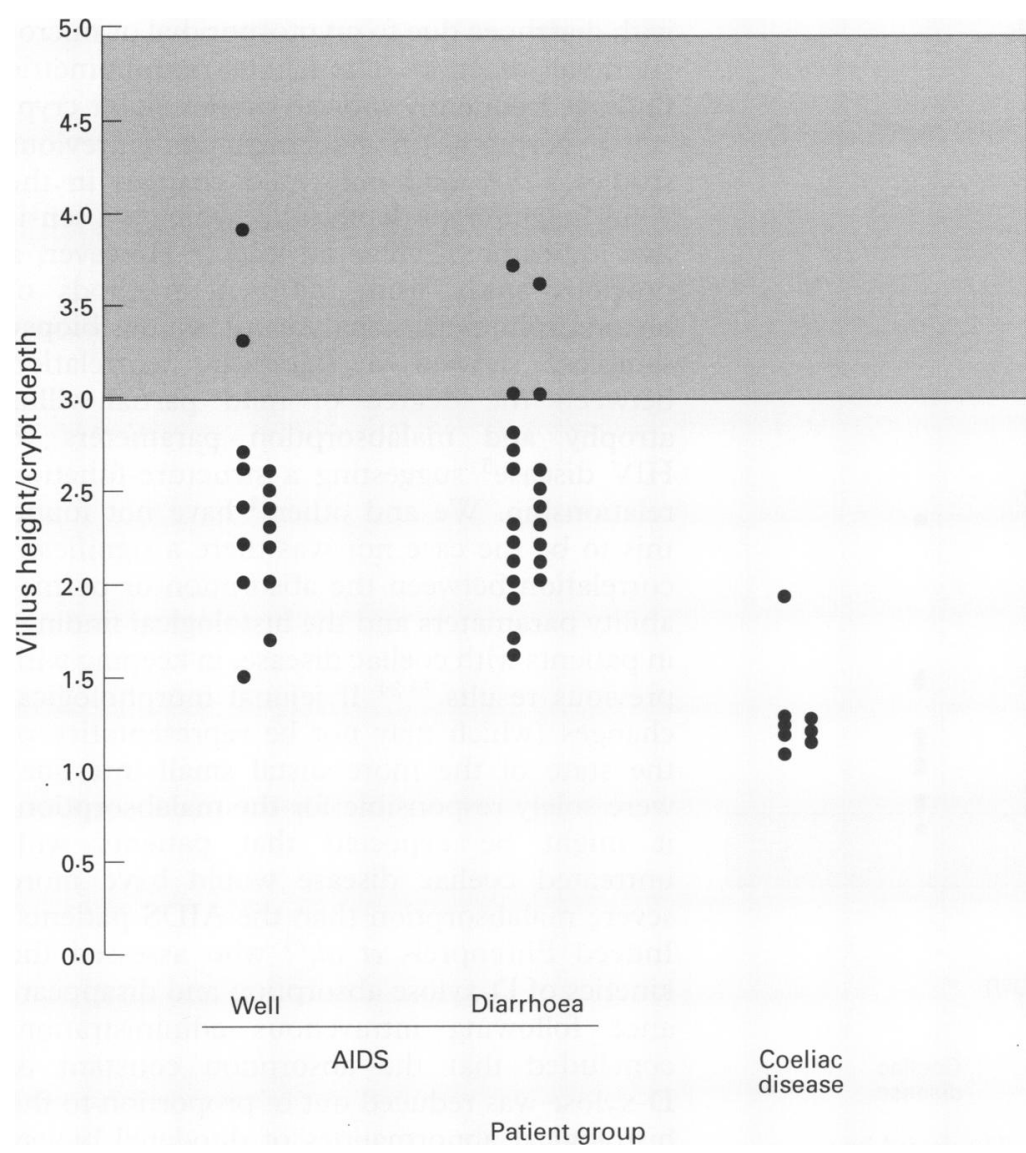

Figure 5: Morphometric analyses of jejunal biopsy samples. Normal villus height/crypt depth ratio is represented within the shaded box. Patients with AIDS have less severe changes than patients with coeliac disease.
2 Miller TL, Orav EJ, Martin SR, Cooper ER, McIntosh K, Winter HS. Malnutrition and carbohydrate malabsorption in children with vertically transmitted human immunodeficiency virus 1 infection. Gastroenterology immunodeficiency virus

3 Ullrich R, Zeitz M, Heise W, L'age M, Hoffken G, Riecken EO. Small intestinal structure and function in patients infected with human immunodeficiency virus (HIV): Evidence for HIV-induced enteropathy. Ann Intern Med 1989; 111: 15-21.

4 Gillin JS, Shike M, Alcock N, Urmacher C, Krown S, Kurtz RC, Lightdale CJ, Winawer SJ. Malabsorption and mucosal abnormalities of the small intestine in the acquired immunodeficiency syndrome. Ann Intern Med 1985; 102: 619-22.

5 Miller ARO, Griffin GE, Batman P, Farquar C, Forster SM, Pinching AJ, Harris JRW. Jejunal mucosal architecture and fat malabsorption in male homosexuals infected with human immunodeficiency virus. $Q \mathcal{F}$ Med 1988; 69: 1009-19.

6 Kapembwa MS, Fleming SC, Griffin GE, Caun K, Pinching AJ, Harris RW. Fat malabsorption and exocrine panching AJ, Harris RW. Fat malabsorption and exocrine pancreatic function in human
tion. $Q \mathcal{M}$ Med 1990; 74: 49-56.

7 Anonymous. 1993 revised classification system for HIV infection and expanded surveillance case definition for AIDS amongst adolescents and adults. Morbidity and Mortality Weekly 1992; 41: 1-18.

8 Park RAA. European AIDS definition. Lancet 1992; 339: 671 .

9 Gazzard BG. Practical advise for the gastroenterologist dealing with symptomatic HIV disease. Gut 1990; 31: 733-5.

10 Connolly MG, Forbes A, Gleeson JA, Gazzard BG. Investigation of upper gastrointestinal symptoms in patients with AIDS. AIDS 1989; 3: 453-6.

11 Garrow JS. Treat obesity seriously. A clinical manual. Edinburgh: Churchill Livingstone, 1981.

12 Slavin G, Sowter C, Robertson K, McDermott S, Paton K. Measurement in jejunal biopsies by computer-aided microscopy. 7 Clin Pathol 1980; 33: 254-61

13 Teahon K, Smethurst P, Levi AJ, Menzies IS, Bjarnason I. Intestinal permeability in patients with Crohn's disease and their first degree relatives. Gut 1992; 33: 320-3.

14 Bjarnason I, Ward K, Peters TJ. The'leaky gut of alcoholism: possible route of entry of toxic compounds. Lancet 1984; i: 179-82.

15 Biarnason I, Williams P, So A, Zanelli G, Levi AJ, Gumpel MJ, Peters TJ, Ansell B. Intestinal permeability and inflammation in theumatoid arthritis; effects of nonsteroidal anti-inflammatory drugs. Lancet 1984; ii: steroidal

16 Hamilton I. Small intestinal permeability. In: Pounder RE, ed. Recent advances in gastroenterology 6. Edinburgh: Churchill Livingstone, 1986: 73-91.

diseases. ${ }^{34}$ Similar findings were reported by Lim et al. ${ }^{35}$

While increased intestinal permeability is a non-specific finding, seen in a variety of situations, ${ }^{13-15283637}$ it may be relevant in the present context that an increase in intestinal permeability is seen in some viral infections. ${ }^{28} 29$ The consequences of increased intestinal permeability are the subject of speculation. In non-HIV related disease it may allow permeation of macromolecules, thereby promoting some of the systemic manifestations of disease, ${ }^{38-41}$ but it is more likely to result in the development of a low grade enteropathy. ${ }^{1415} 18$

In summary, intestinal absorptive capacity and integrity are usually maintained in asymptomatic homosexual patients before the development of AIDS. Increased intestinal permeability is almost invariably found in AIDS but the immediate clinical implications are uncertain. Intestinal malabsorption is common after the development of AIDS and has important implications for nutrition in these patients. Although our results can not be extrapolated to other groups of patients with AIDS (intravenous drug users, haemophiliacs, etc), it is suggested that the severity of malabsorption in homosexuals with AIDS is at times so great as to preclude attempts at supplementation by the enteral route.

This study was funded in part by a MRC project grant. AM is the recipient of an MRC clinician scientist fellowship.

1 Kotler DP, Francisco A, Clayton F, Scholes JV, Orenstein JM. Small intestinal injury and parasitic disease in AIDS Ann Intern Med 1990; 113: 444-9.
17 Menzies IS. Transmucosal passage of inert molecules in health and disease. In: Skadhauge E, Heintze $\mathrm{K}$, eds. Intestinal absorption and secretion. Falk Symposium 36. Lancaster: MTP Press, 1984: 527-43.

18 Bjarnason I, Macpherson AJ, Somasundaram S, Teahon K. Nonsteroidal anti-inflammatory drugs and inflammatory bowel disease. Canadian fournal of Gastroenterol 1993; 7: $160-9$.

19 Bjarnason I, Macpherson AJS, Somasundarm S, Teahon K. Non-steroidal anti-inflammatory drugs and Crohn's Non-steroidal anti-inflammatory drugs and Crohn's disease. In: Scholmeric J, Kruis W, Goebbell H,
Hohenberger W, Gross V, ed. Inflammatory bowel disease: Hohenberger W, Gross V, ed. Inflammatory bowel disease:
pathophysiology as basis of treatment. Falk Symposium no 67. Lan-22.

20 Bjarnason I, Macpherson A, Somasundaram S, Teahon K. Nonsteroidal anti-inflammatory drugs and inflammatory bowel disease. Canadian fournal of Gastroenterol 1993; 7: $160-9$.

21 Menzies IS, Jenkins AP, Heuduan S, Catt SD, Segal MB, Creamer B. The effect of poorly absorbed solute on intestinal absorption. Scand f Gastroenterol 1990; 25: 1257-64.

22 Cummings AG, LaBrooy JT, Stanley 'DP, Roland R, Sherman DJC. Quantitative histological study of Sherman DJC. Quantitative histological study of enteropathy

23 Bjarnason I, Peters TJ, Veall N. A persistent defect of intestinal permeability in coeliac disease as demonstrated by a 51 Cr-labelled EDTA absorption test. Lancet 1983; i: 323-5.

24 Bjarnason I, Marsh MN, Price A, Levi AJ, Peters TJ. Intestinal permeability in patients with coeliac disease and dermatitis herpetiformis. Gut 1986; 26: 1214-9.

25 Ehrenpreis ED, Gulino SP, Patterson BK, Craig RM Yokoo H, Atkinson AJ. Kinetics of D-xylose absorption in pathy. Clin Pharmacol Ther 1991; 49: 632-40.

26 Nelson JA, Wiley CA, Reynolds-Kotler C, Reese CE, Margaretten W, Levy JA. Human immunodeficiency virus detected in bowel epithelium from patients with gastroindetected in bowel epithelium from patients

27 Kotler DP, Reka S, Clayton F. Intestinal mucosal inflammation associated with human immunodeficiency virus mation associated with human immun

28 Noone C. Menzies IS, Banatvala JE, Scopes JW. Intestinal Noone C, Menzies IS, Banatvala JE, Scopes JW. Intestinal
permeability and lactulose hydrolysis in human rotaviral permeability and lactulose hydrolysis in human rotaviral differential sugar permeation. Eur $\mathcal{F}$ Clin Invest 1986; 16: 217-25. pathophysiology as basis of treatment. Falk Symposium no patients with human immunodeficiency virus entero- 
29 Parrili G, Cumo R, Nardone G, Maio G, Izzo CM, Budillon G. Investigation of intestinal function during acute viral hepatitis using combined sugar load. Gut 1987; 28: 1439-44.

30 Kapembwa MS, Fleming SC, Sewankambo N, Serwadda D, Lucas S, Moody A, et al. Altered small-intestinal permeability associated with diarrhoea in human-immunodeficiency-virus-infected caucasian and African subjects. Clin Sci 1991; 81: 327-34.

31 Kynaston JA, Fleming SC, Laker MF, Pearson ADJ. Simultaneous quantification of mannitol, 3-O-methyl glucose, and lactulose in urine by HPLC with pulsed electrochemical detection, for use of intestinal permeability. Clin Chem 1993; 39: 453-6.

32 Ukabam SO, Homeda MA, Cooper BJ. Small intestinal permeability in Sudanese subjects: Evidence of tropical

33 Cook CG, Menzies IS. Intestinal adsorption and unmediated permeation of sugars in post-infective tropical malabion 1986; 33: 109-16.

34 Ott M, Lembcke B, Staszewski S, Helm EB, Caspary WF Intestinal permeability in patients with acquired immunodeficiency syndrome (AIDS). Klin Wochenschr 1991; 69: 715-21.

35 Lim SG, Menzies IS, Lee CA, Johnson MA, Pounder RE.
Intestinal permeability and function in patients infected with human immunodeficiency virus. Scand with human immunodeficienterol 1993; 28: 573-80.

36 Bjarnason I, O'Morain C, Levi AJ, Peters TJ. The absorption of 51Cr EDTA in inflammatory bowel disease. Gastroenterology 1983; 85: 318-22.

37 Menzies IS, Pounder R, Heyer S, Laker MF, Bull J, Wheeler PG, Creamer B. Abnormal intestinal permeability to sugars in villus atrophy. Lancet 1979; ii: $1107-9$.

38 Ferry DM, Butt TJ, Broom MF, Hunter J, Chadwick VS Bacterial chemotactic oligopeptides and the intestinal mucosal barrier. Gastroenterology 1989; 97: 61-7.

39 Davin JC, Forget P, Mahieu PR. Increased intestinal permeability to $(51 \mathrm{Cr}) \mathrm{EDTA}$ is correlated with IgA immune complex-plasma levels in children with IgA-associated nephropathies. Acta Pediatr Scand 1988; 77: 118-24.

40 Ramage JK, Stanisz A, Scicchitano R, Hunt RH, Perdue Rame JK, Stanisz A, Scicchitano R, Hunt RH, Perdue $\mathrm{MH}$. Effects of immunologic reactions on rat intestinal epithelium. Correlation of increased intestinal permeability to chromium 51 labelled ethylenediaminetetraacetic acid and ovalbumin during acute inflammation and anaphylaxis. Gastroenterology 1988; 94: 1368-75.

41 Sanderson IR, Walker WA. Uptake and transport of macromolecules by the intestine: Possible role in clinical disorders (an update). Gastroenterology 1993; 104: 622-39. 